\title{
Processo de Criação e Gênese Imaterial da Poesia de Luiz Bacellar
}

Luana Aguiar Moreira Allison Marcos Leão

\section{Introdução}

ENTRE OS ANOS DE 2015 E 2019, UMA EQUIPE DO GRUPO DE PESQUISAS “INVESTIGAÇÕES OBRE MEMÓRIA Cultural em ARTes e literatura", Vinculado no Programa de Pós-GraduaÇÃo EM Letras E ARTes da UNIVERSIDADE DO ESTADO DO AMAZONAS (PPGLA-UEA), REALIZOU ESTUdOS SOBRE A OBRA DO POETA AMAZONENSE LUIZ BACELLAR (1928-2012), especialmente sobre seu título mais emblemático, o livro de estreia Frauta de barro, cuja primeira edição foi em 1963. Os participantes da equipe (dois docentes titulares do PPGLA: Luciane Páscoa e Allison Leão; dois estudantes de mestrado: Fábio Fadul de Moura e Rômulo Nascimento; duas estudantes de graduação/iniciação científica: Valquíria Luna Arce de Lima e Luana Aguiar Moreira) desenvolveram planos de trabalhos próprios, porém vinculados ao projeto mais amplo coordenado pelo docente Allison Leão. Este contou com o financiamento da UEA no âmbito do Programa de Pesquisa e Produtividade Acadêmica dessa instituição. Por aproximação ao campo dos estudos em arquivos literários, substrato de uma das linhas do programa de pós-graduação em que a equipe do projeto atuava, esses estudos privilegiaram os aspectos que, na obra de Bacellar, evocam certas práticas ou princípios do ser do arquivo, tais como o acúmulo, a coleção, a repetição, a série e o registro mnemônico. Em fases intermediárias da pesquisa, tentamos reunir alguns desses temas para compreender o sentido da "repetição em diferença" que se pode notar na sequência editorial das sete versões que essa obra teve quando em vida do poeta. Argumentamos então que a poética de Bacellar vai se estabelecendo por meio de certas chaves a princípio exteriores à sua poesia, como a música (tout court), as influências artísticas e a tradição literária que lhe serviram de fonte criadora, ao mesmo tempo em que internaliza traços dessas matrizes transfigurando-os num ethos próprio e numa performance estética que teria como um de seus efeitos a própria repetição; em outras palavras, canibalizando aspectos de tais matrizes, assimilando-os a um ser na verdade gestado por elas, a poesia de Bacellar não poderia ter outra forma de expressão que não fosse o provisório, dado o espectro múltiplo e transitório que circunda as bases de sua criação. Assim, a materialidade da obra está submetida a uma energia difusa que a antecede e promove uma força ininterrupta que a sucede, como as reedições nos fazem crer.

Contudo, por se tratar de um autor educado numa pedagogia de veiculação e circulação que conhecemos pelos nomes de livro e mercado editorial, haveríamos de nos deparar sempre com a prevalência que ele mesmo talvez tenha dado a esse modo, hipótese reforçada pelo fato de que, com sete edições, entretanto, passados oito anos da morte de Luiz Bacellar, nada do que chamaríamos seus "documentos de processo" foi encontrado até agora. Talvez seduzidos por essa aparente premência do livro, aliada à ausência dos documentos de processo, tenhamos passado algum tempo a buscar, no confronto com as páginas, as marcas de seu processo de criação, buscando, como que numa genética reversa, verificar as marcas do processo no livro acabado, como uma arqueologia da superfície, apoiados na tese (não de todo agora descartada) de que o escrito (o livro) guardava em 
si mesmo suas camadas de construção. Daí que, nas primeiras leituras que fizemos de Frauta de barro, nos concentramos em elencar as várias referências à música e ao seu universo; inventariamos a mobília íntima, os objetos do cotidiano transmutados em poesia; registramos a série literária que se instila no corpo da obra, como uma biblioteca mais ou menos visível; mapeamos os espaços da cidade a que obra alude, como um mapa fantasmagórico de uma Manaus para sempre perdida. Isso quer dizer que buscamos encontrar a força das disposições criadoras onde elas já deixaram de ser fontes e passaram a ser código, registro, por mais polissêmicos que fossem seus enunciados e seus efeitos. E, encantados pelo mundo reproduzido em forma de miniatura e pequena coleção lírica, nos tornamos nós mesmos colecionadores dos escombros do mundo que só o poeta viu.

No entanto, em fase mais avançada do trabalho, em que tratávamos dos vestígios da cultura popular de base especialmente oral na obra de Bacellar (plano de trabalho de Luana Aguiar e Allison Leão), fomos progressivamente chamados a pensar noutra perspectiva. De fato, nenhum dos componentes de Frauta de barro até então por nós estudados havia se revelado tão potencialmente aniquilador do estatuto de materialidade da escrita ou tão rebelde ante as vontades codificadoras do cânone ocidental, a que se vincula o poeta, quanto aqueles advindos do universo da cultura oral. Observamos, por exemplo, em relação ao campo da música, uma profusão lexical disposta ao longo dos poemas, que convoca mais elementos codificadores em seu mundo de origem; em relação às matrizes literárias o resultado da leitura é um acúmulo de camadas de significantes do trânsito de obras influenciadoras. Mas essa esfera do que é cognoscível pelo registro perde força conforme avançamos no campo da oralidade.

Essa paulatina evasão do signo que se apresentava conforme progredíamos nas ponderações acerca do grau de relação da obra com possíveis bases orais contrariava, de certo modo, o caminho que vínhamos traçando, uma vez que até ali, nos ancorávamos em uma constelação de abordagens, conceitos e métodos que pendem, em maior ou menor grau, para um apelo concreto do vestígio, como a filologia e a crítica genética - no caso desta, aqui pensada apenas sua abordagem inicial (embora ainda mais frequente), calcada na investigação em dossiês ou documentos de gênese. Note-se, por exemplo, que no riquíssimo "horizonte genético" que Pierre-Marc de Biasi ${ }^{1}$ visualizava para os estudos de gênese no início deste século, há uma ampliação para campos muito além da literatura (corpo de origem da crítica genética), ao mesmo tempo em que o estatuto de concretude na visão sobre os vestígios de criação pouco ou em nada altera. Para o caso do nosso estudo, esses usos algo fora de lugar de certos conceitos deram bons resultados, pois noções como as de "variantes editoriais", "processo" e "descontinuidade" ajudaram a revelar aspectos importantes do acúmulo de diferenças entre as sete edições do livro. Em suma, permanecem importantes as ferramentas dos estudos de gênese mesmo quando nela não há um corpo evidente, respeitados os princípios que estão por trás desses instrumentos de compreensão do processo.

Ainda assim, é necessário assinalar que, em termos de poética, nada do que pode refluir para o impreciso e o incorpóreo prescinde de um patamar visível, audível, enfim do corpo da escrita. Assim também será em relação ao aspecto de que trataremos aqui. Porém, nosso horizonte está além, ou principalmente aquém, da escrita e do escrito. Nesses termos, não se chega a uma fruição de caráter abstrato ou metafísico sem antes atravessar a camada perceptual própria da arte. Ou seja, atravessar os dados e as marcas tangíveis a partir dos registros resgatáveis para tentar compreender a presença mais sutil de uma cosmovisão.

\footnotetext{
${ }^{1}$ BiASI, P.-M. de. O horizonte genético. In: ZulAR, R. Criação em processo: ensaios de crítica genética. São Paulo: Iluminuras, 2002. p. 219-252.
} 
Desta forma, com este texto, pretendemos pensar a noção de processo de criação à luz de elementos cujo rastro seja menos concretamente verificável do que aquilo que se encontra normalmente privilegiado como "documento de processo". Propomo-nos a investigar de que maneira e em quais proporções a oralidade e a cultura popular se manifestam nos poemas. Primeiro, serão observadas questões temáticas e formais, um mapeamento das histórias populares presentes na obra; em seguida, observaremos uma linha de discurso recorrente nessas representações, baseando-nos na concepção de cultura cômico-popular de Bakhtin. Para isso, selecionamos as sessões "Romanceiro suburbano", com 12 poemas, "Sonetos provincianos" e "Três noturnos municipais", com três sonetos cada um.

\section{Impressões da voz no corpo da escrita}

Em Frauta de barro, é possível compreendermos a representação da cultura popular em pelo menos duas categorias gerais: primeiro, sua manifestação a partir de elementos de tradição oral, isto é, poemas que recriam "contos" populares; em segundo lugar, elementos corpóreos e simbólicos do cotidiano popular, como a dança, a brincadeira e a culinária. Tais categorias, no entanto, não aparecem de forma isolada, mas sim se relacionam mutuamente, recriando o universo popular da obra.

A oralidade, seja em maior ou em menor grau, faz parte da composição cultural de todas as sociedades desde comunidades indígenas, onde os mitos, transmitidos de forma oral, representam a sua gênese e identidade, até em ambientes urbanos, em que histórias populares e canções têm importante papel no cotidiano. A poesia oral, como pode ser chamada, é uma necessidade humana; é inerente às sociedades desde a sua formação, sendo impossível escaparmos da poeticidade da voz, de sua força e permanência. Segundo Paul Zumthor ${ }^{2}$, em sua Introdução à poesia oral, a performance, elemento fundamental da poética oral, é sempre presente; ela é "a ação complexa pela qual uma mensagem poética é simultaneamente, aqui e agora, transmitida e percebida", onde o "locutor, destinatário, circunstâncias [...] se encontram concretamente confrontados, indiscutíveis". Isso tem por efeito a performance só existir no tempo presente, em execução, e somente ser reconhecível quando em sua transmissão e, consequentemente, no seu momento de recepção. A escrita, a gravação ou qualquer outro meio de midiatização da voz jamais englobará todo o significado e a presença real da voz poética, quer pela perda da simultaneidade a que nos referimos, quer pela dissolução do caráter espacial da tridimensionalidade.

Se, por um lado, não temos mais acesso a contos orais como aqueles produzidos no passado em Manaus, dos que se apropria o poeta, isto é, se não os conhecemos quando criados e reproduzidos em seu tempo, por outro temos como os reconhecer em Frauta de barro por meio de uma recriação poética. Obviamente esse contato já não se dá pela oralidade, mas por algo que permanece atrelado àquele modo de composição, tanto em relação à forma quanto ao ritmo poético, como se a poesia de Bacellar, por sua performance, ressoasse fantasmagoricamente as fontes orais das quais se alimentara.

Nos estudos de Mário Ypiranga Monteiro (1909-2004), importante pesquisador de temas amazônicos, encontramos dados a respeito de alguns contos populares recriados na obra de Bacellar. Em Roteiro do Folclore Amazônico, Monteiro $^{3}$ realiza uma compilação etnográfica da cultura amazônica, agrupando uma miríade de

\footnotetext{
${ }^{2}$ ZUMTHOR, P. Introdução à poesia oral. Belo Horizonte: Editora UFMG, 2010. p. 31.

${ }^{3}$ MonTEIRo, M. Y. Roteiro do folclore amazônico. 2. ed. Manaus: Edições Fundação Cultural do Amazonas, 1974.
} 
contos, lendas, canções, poemas, isto é, um conjunto de "conhecimentos populares", diversas vezes expressos narrativamente. Dentre esses registros, inseridas no campo da literatura de cordel, encontram-se três narrativas recriadas/recontadas em Frauta: Santa Etelvina, o caso da Neca e a história do alferes esquartejado. A poesia popular e, em especial, a literatura de cordel, possui estreita relação com os acontecimentos do cotidiano que, de algum modo, envolvem o imaginário popular. Não é por acaso que os vestígios de oralidade em Frauta de barro são compostos por histórias que foram contadas, anteriormente, em poesia de cordel.

Atualmente, o único registro da época (início do século $\mathrm{XX}$ ) a que temos acesso é o folheto Os horrores de Manaus, de Antônio Mulatinho, poeta nordestino radicado em Manaus. O artista recria, nos 64 versos de "A infeliz Etelvina em março de 1901" - assim como Bacellar, no poema "Santa Etelvina", de Frauta -, a narrativa oral popular sobre uma moça que fora brutalmente assassinada por um enlouquecido pretendente. A triste história comoveu a população da cidade, que postumamente atribuiu-lhe o epíteto de santa. Atualmente, esse folheto específico de Antonio Mulatinho encontra-se no acervo da Biblioteca Mário Ypiranga Monteiro, localizada no Centro Cultural dos Povos da Amazônia, em Manaus, enquanto outra parte de sua obra está no acervo do Instituto de Estudos Brasileiros, na coleção de folhetos de cordéis de Mário de Andrade.

Ao compararmos os poemas, é notória a semelhança; afinal, Bacellar dialogou, não só em "Santa Etelvina" mas em todos os poemas de "Romanceiro suburbano", com o gosto formal da poesia popular, utilizando-se amplamente nessa parte do livro da redondilha, tal como se usa em cordel. Se lermos trechos de ambos os poemas em sequência, poder-se-ia dizer que constituem uma sequência, tamanha a similaridade:

\section{Chora toda a criação, \\ Quando vê tão triste sina, \\ Daquela triste infeliz! \\ Que foi chamada Etelvina, \\ No amor materno criada \\ Desde o berço, pequenina ${ }^{4}$}

E, hoje, em dia de Finados

Em memória dos martírios

Para a sua sepultura

Levam rosas, levam lírios,

Levam velas, levam círios,

Oração, promessa, rogo,

E a sepultura é uma pira

Coberta de cera e fogo. ${ }^{5}$

\footnotetext{
${ }^{4}$ Mulatinho, A. Os horrores de Manaus. 4. ed. Secção d'A Tarde. Manaus, 1939. p. 39.

${ }^{5}$ BACELLAR, L. Frauta de barro. 9. ed. Manaus: Editora Valer, 2011. p. 69.
} 
E muito embora Antônio Mulatinho tenha escrito seus versos em 1904, muito antes do nascimento de Bacellar, o recontar do poeta amazonense evidencia a forma como a oralidade era presente no imaginário popular. Até o final da década de 1970, o túmulo de Etelvina de Alencar, localizado no Cemitério São João Batista, recebia o maior número de homenagens em dia de Finados, como mencionam os versos anteriormente expostos.

Há, nos poemas de Frauta, uma linha tênue entre a criação e o real, transfigurando-se essa dualidade em uma ideia apenas: a poesia. Um exemplo significativo é o poema "Romance do esquartejado", alusivo à história de um alferes que, no final do século XIX, foi encontrado morto, sem que se soubesse a causa e o responsável pelo assassinato. Segundo as pesquisas de Monteiro, o caso foi um "assassinato bárbaro e misterioso, ocorrido no bairro dos Tocos, em Manaus, de um alferes da milícia. O cadáver foi encontrado num saco e o crime, jamais descoberto

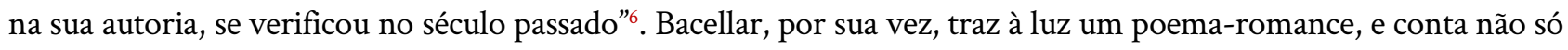
como o corpo foi encontrado, como também inclui os motivos do crime, isto é, o flagrante de um adultério:

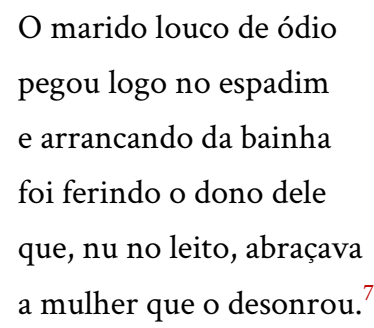

Além da tradição oral, outros aspectos fundamentais situam-se, principalmente, dentre os elementos simbólicos da cultura popular que, em Frauta de barro, são representados através da música, do lúdico e da culinária. A musicalidade aparece não somente como estrutura poética, visível em uso específico de métrica ou de figuras de linguagem, mas também como um ritmo constante da obra, entrelaçando os poemas que a compõem. "Torneio de papagaios" e "Ciranda à roda de um tronco" (também relacionada à questão da música) remetem-nos à ludicidade infantil própria de um tempo passado:

\title{
TORNEIO DE PAPAGAIOS
}

\author{
$\mathrm{Na}$ liça das nuvens \\ a justa do azul: \\ estrelas e arraias \\ sóis e paparolas \\ pipas e pandorgas \\ briais de papel, \\ de seda, paquifes \\ de tiras de trapo [.. $]^{8}$
}

\footnotetext{
${ }^{6}$ Op. cit. p. 422-423.

${ }^{7}$ Op.cit. p. 60.

${ }^{8}$ Op. cit. p. 70.
} 
O tacacá, iguaria amazônica, é descrito em "Receita de tacacá", único poema do livro que alude à culinária da região - embora não possua, em sua totalidade, apenas a mera significação descritiva da comida, trazendo também sentido relacionado à sexualidade. Entrementes, ao lançar mão da culinária como um dos integrantes de seu "Romanceiro Suburbano", Bacellar a incorpora, juntamente com a ludicidade e a música, como elemento de identidade e pertencimento cultural:

\author{
RECEITA DE TACACÁ \\ Ponha, numa cuia-açu \\ ou numa cuia-mirim \\ burnida de cumatê: \\ camarões secos, com casca, \\ folhas de jambu cozido \\ e goma de tapioca. \\ Sirva fervendo, pelando, \\ o caldo de tucupi, \\ depois tempere a seu gosto: \\ um pouco de sal, pimenta- \\ malagueta ou murupi. \\ Quem beber mais de 3 cuias \\ bebe fogo de velório. \\ Se você gostar me espere \\ na esquina do purgatório. ${ }^{9}$
}

Embora "Romanceiro suburbano" assuma um caráter festivo, as duas sessões conseguintes, por outro lado, apesar de remeterem a temas similares, o fazem em tom grave e memorialístico. Para isso, se tomarmos $A$ sensibilidade dos punhais, ensaio de Marcos Frederico Krüger, como suporte crítico, compreenderemos o lugar dos "Sonetos provincianos" e "Três noturnos municipais" na obra de Bacellar. Segundo Krüger ${ }^{10}$, Frauta de barro constitui uma viagem do eu lírico "por um mar alegórico, buscando a afirmação de uma individualidade recalcada" e, também, uma viagem temporal e não linear pela própria literatura. Isto é, ao longo dos poemas, o eu lírico - jovem poeta inexperiente, no início - demonstra aos poucos desenvolver suas habilidades poéticas, que são demonstradas na própria forma dos poemas, que vão se sofisticando com estruturas mais e mais complexas no transcorrer das seções do livro.

Dessa forma, se anteriormente cantava-se uma "Ciranda à roda de um tronco" em tom alegre e infantil, onde uma mangueira "do velho tronco enrugado" servia como refúgio aos enamorados, e suas folhas eram "Como um colar de rainha / Sobre um dorsel desfiado"11, depois, tais lembranças são apenas "Cantilenas nostálgicas e antigas, / fados, solaus, que falam da cachopa / da Póvoa, dos amantes, das amigas” ${ }^{12}$. A forma clássica do

\footnotetext{
${ }^{9}$ Op. cit. p. 72.

${ }^{10}$ KRÜGER, M. F. A sensibilidade dos punhais. Manaus: Edições Muiraquitã, 2011. p. 74-75.

${ }^{11}$ Op. cit. p. 51.

${ }^{12}$ Ibidem, p. 78.
} 
decassílabo contrapõe-se à métrica popular anterior, caracterizando tanto a mudança estética de desenvolvimento do poeta, quanto a sua perspectiva de mundo, em relação à cultura popular: antes, alegre e ingênuo; ao amadurecer, distante e nostálgico.

\section{o corpo invisúvel da voz}

Recurso extremamente complexo e sagaz, a ironia exige habilidades tanto do formulador dos fenômenos e linguagem irônicos, quanto do receptor, que precisa assimilá-la para atribuir-lhe sentido. Conforme nos revela Lélia Duarte ${ }^{13}$, em Ironia e humor na literatura, diversos estudos já demonstraram a importância da ironia para a literatura, evidenciando-a, inclusive, como um dos traços de distinção entre a literatura clássica e a literatura moderna; pois, se anteriormente, por exemplo, o narrador clássico era onipresente e distante quanto aos fatos narrados, sem inserir-se como uma determinante, o narrador moderno, contrariando essa lógica, passa a ter poder e voz fundamentais na narrativa. O narrador moderno, dessa forma, pode ser uma consciência na narrativa que cria estratégias para ludibriar o leitor.

A ironia, embora seja mais facilmente compreendida e estudada dentro de narrativas, já que a presença e voz do narrador é mais evidente, também tem espaço na lírica. Tal situação é perceptível em Frauta de barro, obra em que o eu lírico, um perspicaz observador da cultura e seus fenômenos, demonstra ter uma visão cômico-popular de mundo, de onde o traço irônico condutor da narrativa que paira sobre a cultura de um povoado. A esse respeito, podemos nos basear nos estudos de Makhail Bakhtin que em Cultura popular na Idade Média e no Renascimento analisa, a partir da obra do escritor renascentista François Rabelais, as manifestações e dimensões da cultura popular, sobretudo o rito carnavalesco, núcleo daquelas culturas. Rabelais, diferentemente de outros escritores do período, está mais intimamente ligado às fontes populares, que serviram como base para a sua produção artística - e a isso, segundo Bakhtin, se deve a qualidade de sua obra.

Dessa forma, a cultura popular medieval teria fundamentos cômicos de mundo e utilizaria a festividade do carnaval como base dessa manifestação. Segundo Bakhtin, “o riso carnavalesco é em primeiro lugar patrimônio do povo [...]; todos riem, o riso é 'geral'; em segundo lugar, é universal, atinge a todas as coisas e pessoas [...], o mundo inteiro parece cômico e é percebido e considerado no seu aspecto jocoso, no seu alegre relativismo” ${ }^{4}$. Soma-se a isso a sua ambivalência, isto é, o modo "alegre e cheio de alvoroço, mas ao mesmo tempo burlador e sarcástico” em que "nega e afirma, amortalha e ressuscita simultaneamente”. Impossível defini-lo como negativo ou positivo, pois é, ao mesmo tempo, os dois.

Em Frauta de barro, esse fenômeno se manifesta constantemente: figuras religiosas aparecem, ao mesmo tempo, como homens comuns e bíblicos, como profanos e sagrados, "altos" e "baixos”. "Balada do bairro do Céu”, além de configurar uma tentativa de proximidade com a oralidade - "Corre xente! Chega povo!" -, também narra uma briga entre Cristo e Pedro; ao mesmo tempo que são o porteiro do clube de futebol e jogador do time (ironicamente) intitulado Todos os Santos, são, também, Cristo e Pedro personagens bíblicos:

- Aonde é isso?

\footnotetext{
${ }^{13}$ DUARTE, L. P. Ironia e humor na literatura. Belo Horizonte: Editora PUC Minas; São Paulo: Alameda, 2006.

${ }^{14}$ BAKhtin, M. A cultura popular na Idade Média e no Renascimento: o contexto de François Rabelais. São Paulo: Hucitec; Brasília: Editora da Universidade de Brasília, 1999. p. 10.
} 


$$
\begin{aligned}
& \text { - No Céu! } \\
& \text { [...] } \\
& \text { - Mas... quar Cristo? } \\
& \text { - O carapina! } \\
& \text { - E quar Pedro? } \\
& \text { - O pescadô! }{ }^{15}
\end{aligned}
$$

No entanto, o rito carnavalesco descrito por Bakhtin não se assume apenas como festividade, mas como a própria representação da vida, alçando-se assim a um ethos que extrapolou a temporalidade medieval. Segundo o autor, "o carnaval não é de maneira alguma a forma puramente artística do espetáculo teatral e, de forma geral, não entra no domínio da arte. Ele se situa entre a arte a vida" e, dessa forma, "é impossível escapar a ela, pois o carnaval não tem nenhuma fronteira espacial" ${ }^{16}$. De forma semelhante, tal significação da vida é incorporada em Frauta de barro, quando a obra assume um caráter risível e cômico que entremeia toda a sua lógica de composição e visão de mundo.

A presença de figuras de natureza religiosa faz-se constante na obra (como já observado em "Balada do bairro do Céu"). Esses elementos não seriam gratuitos, visto que o riso carnavalesco se manifesta como uma resposta um riso libertador - às instituições dominantes, como a Igreja. Assim, os doze poemas de "Romanceiro suburbano" apresentam, em sua maioria, uma perspectiva de "inversão de valores" ou de "mundo ao avesso", como o poema "Paróquias de Manaus": nele, algumas paróquias da cidade antiga são representadas por tercetos que lhe descrevem ou as representam por meio de imagens burlescas. Isto é, a monumentalidade canônica da Igreja reduz-se aos pequenos poemas, demonstrando-se um traço ironizante quanto à relação forma/conteúdo dos poemas.

Ademais, o poema dedicado à paróquia de Educandos, nesse sentido, apresenta-se como um exemplo significativo, em que a fala - contraditória - do padre é convertida em sete sílabas poéticas: "Se peito de moça fosse / buzina ninguém dormia / na paróquia do Educandos" ${ }^{17}$. Além da comicidade relacionada à "lógica" de pensamento do padre, considerada contraditória (visto que não seria apropriada a uma figura religiosa), também seria burlesco e caricato imaginar a (im)possibilidade de um "peito de moça" se transformando em buzina.

\section{Considerações Finais}

Apesar das maneiras de ser por vezes intangíveis e abstratas da oralidade, as pesquisas sobre a poética da voz, ligada à sociedade que a produz, muito têm a acrescentar aos estudos literários; principalmente se concebermos que o nascimento da literatura se deu na voz, na canção e no ritmo; embora muitas vezes a cultura oral, tida como "atrasada", seja subjugada à escrita, esta representando o que é científico, concreto e real ${ }^{18}$. Dessa forma, seria ilegítimo não reconhecer as reminiscências de uma cultura oral, ligada a um tempo-espaço cultural de uma comunidade, presentes na lírica de Bacellar.

\footnotetext{
${ }^{15}$ Op. cit. p. 52.

${ }^{16}$ Op. cit. p. 6.

${ }^{17}$ Op. cit. p. 74.

${ }^{18}$ ZUMTHOR. Op. cit.
} 
Partindo do visível das formas que reverberam da cultura popular na poesia de Bacellar, chegando a níveis impalpáveis de infiltração daquela ética numa poética, não esperamos que isso signifique um retorno a um pretenso estado ideal da poesia, uma idade de ouro da voz, como frequentemente é entendida a própria cultura popular. As conclusões a que os dados e análises acima nos fizeram chegar nos sugerem que há ao menos três terrenos nos quais a reflexão ainda poderá avançar.

Primeiramente, sabemos que redirecionar o sentido da relação entre fontes (especialmente quando estas são imateriais) e obra, rejeitando a submissão daquelas diante destas, significa uma postura crítica sobre a noção de tempo teleológico em que fomos catequizados. No caso de Frauta de barro, além de serem fontes, as bases orais podem interferir na leitura da obra quando a elas retornamos, o que significa dizer que processos anteriores ao estabelecimento da obra podem alterá-la em sua recepção, na medida em que se toma conhecimento dessas estruturas pré-existentes. Da mesma maneira, a visão cômico-popular, sendo variável na própria História, retroativamente alteraria também uma obra concebida sob seus princípios, como naquele caso pensado por Borges em que Kafka influencia seus precursores.

Em segundo lugar, nos afastamos um pouco da própria tradição do documento a que muitas vezes os estudos dos processos de criação se aferram. Sem negar a importância desse paradigma em incontáveis campos do pensamento, incluídos os estudos literários, há que se admitir que ainda assim se trata de uma tradição herdada de culturas europeias que não apenas a nos legaram, mas transmitiram junto com isso, muitas vezes, a subordinação do imaterial ou de tudo aquilo que escapa ao universo da escrita. O maior problema está no significado dessa hierarquização, pois ela decorreria das concepções de tempo e história fundamentalmente conflitantes entre a tradição europeia e as tradições nativas da América, como já advertiu Édouard Glissant ${ }^{19}$. Na tradição europeia um dos ratificadores de suas muitas teleologias é haver o documento (ou o elemento material que o valha) na origem da História. Como poderíamos fazer avançarem os estudos de processo de criação, por exemplo, em um campo da criação crescente como tem sido a literatura de autoria indígena, em cuja base está a oralidade não apenas como fonte mas como o próprio ethos que a preenche?

Por fim, há um potencial de mais uma vez nos lembrarmos que uma obra não se esgota na figura delineável de um autor. Sem dúvida, várias abordagens já dão conta disso - como as noções de intertexto e dialogismo; ou outras que já desidealizaram o trabalho do autor - como o faz a própria crítica genética. Entretanto, a percepção de que fontes orais interferem na criação de determinada obra não apenas desestabiliza a noção tradicional de autor que herdamos do século XIX, pois, além de levá-la para mais perto do limite da dissolução que separaria sujeito e coletividade, revela um comprometimento mútuo de criação e recriação da arte que dá forma aos fantasmas da comunidade enquanto por eles mesmos é modulada.

\section{Referências}

BACELLAR, L. Frauta de barro. 9. ed. Manaus: Editora Valer, 2011.

BAKHTIN, M. A cultura popular na Idade Média e no Renascimento: o contexto de Fraçois Rabelais. São Paulo: Hucitec; Brasília: Editora da Universidade de Brasília, 1999.

\footnotetext{
${ }^{19}$ Apud PINO, C. A.; ZULAR, R. Escrever sobre escrever: uma introdução crítica à crítica genética. São Paulo: Martins Fontes, 2007. p. 33-34.
} 
BIASI, P.-M de. O horizonte genético. In: ZULAR, Roberto. Criação em processo: ensaios de crítica genética. São Paulo: Iluminuras, 2002. p. 219-252.

DUARTE, L. P. Ironia e humor na literatura. Belo Horizonte: Editora PUC Minas; São Paulo: Alameda, 2006. KRÜGER, M. F. A sensibilidade dos punhais. Manaus: Edições Muiraquitã, 2011.

MonteIro, M. Y. Roteiro do folclore amazônico (Tomo II). 2. ed. Manaus: Edições Fundação Cultural do Amazonas, 1974. (Etnografia Amazônica, I).

Mulatinho, A. Os horrores de Manaus. 4. ed. Secção d'A Tarde - Barroso. Manaus, 1939.

PINO, C. A.; ZULAR, R. Escrever sobre escrever: uma introdução crítica à crítica genética. São Paulo: Martins Fontes, 2007.

ZUMTHOR, P. Introdução à poesia oral. Belo Horizonte: Editora UFMG, 2010. 